\title{
Kivialan opettamisen haasteet aikuiskoulutuksessa
}

\begin{abstract}
Geologian lähialojen, biologian, maantieteen, kemian ja fysiikan, opetusoppi eli didaktiikka on meillä jo vanhaa perua. Entä miten on itse geologian laita? Sen opettamista ei Suomessa liene paljoa pohdittu eihän geologia ole kouluainekaan.
\end{abstract}

TÄMÄ PUHEENVUORO ei ole didaktikon, vaan työväen- ja kansalaisopistojen kivikurssien vetäjän, joskus kouluissakin sijaisena olleen geologin puheenvuoro. Keskityn joihinkin ongelmakohtiin, joiden tiedostamisesta saattaisi olla hyötyä kansalaisopistojen opettajalle. Lopussa esittelen työmenetelmän nimeltään oppimissykli kivikuntaan sovellettuna.

\section{GEOLOGIAN "SYRJINNÄN" SYITÄ}

Kivialan opettamista ja oppimista ei millään muodoin ole hemmoteltu helppoudella. Geologiaan ei ole ollut tapana puuttua silloin, kun käsitellään muuta luontoa. Esimerkiksi biologiassa lajien väliset rajat eli värit, muodot ja elintavat ovat selviä, ja arkikielessä käytetään niiden suomalaisia nimiä. Jopa sellaisilla eliöillä, joita Suomessa ei esiinny, on hyvin usein kotimaiset nimet. Emme myöskään sano betula, pinus ja picea, vaan koivu, mänty ja kuusi.
Tähän verrattuna geologiaa "syrjitään”. Kivialalla vieraat eliöt voivat olla myös nimeltään vierasperäisiä, kuten esimerkiksi gemssi. Se on selvästi rajattu, muista eliöistä poikkeava käsite. Entä gneissi? Se on taas käsitteenä niin laaja, liukuva ja moniselitteinen, ettei sata vuotta sitten vaikuttaneen geologi J. J. Sederholmin jälkeen moni liene uskaltanut sitä kovin tarkasti määritellä. Metamorfisten kivien määritelmiä ei ole sovittu edes kansainvälisesti, kuten magmakivien. Aikoinaan koulussa sentään opittiin tunnistamaan graniitti ja gneissi. Arvelisin, että moni nyt peruskoulunsa päättävä nuori ei niitä tunne.

Geologialle on ominaista nimien, termien ja käsitteiden hyperrunsaus, vieraskielisyys, kirjavuus, jopa horjuvuus. Juuri millään ei ole geologiassa vain yhtä nimeä, vaan parhailla jopa kymmeniä. Toisaalta aivan eri asioilla voi olla melkein sama nimi: esimerkkeinä graniitti ja granaatti sekä andesiini ja an- 
desiitti. Termit ovat usein paitsi vieraskielisiä, myös vaikeasti lausuttavia ja vaikeasti opittavia, kuten mikrokliiniporfyroblastinen kaligraniitti. Tämä on suuri haaste niin opettajalle kuin oppijallekin.

\section{MONESSA MUKANA}

Millainen olisi tilanne, jos kouluissa ei nykyään olisi ketään, joka osaisi opettaa lapsille tavallisimpien kasvien ja eläinten nimiä ja ominaisuuksia?

Tämä on todellisuutta geologian osalta, vaikka kyseessä ei olekaan kouluaine. Geologia ei silti ole mikään marginaalinen tiedonala. Kirjaimellisesti kaikki lepää geologian eli kallio- ja maaperän harteilla. Metsät, pellot ja puutarhat imevät ravinteensa maaperästä, jossa on kasvien ehdottomasti tarvitsemia, kallioperästä rapautuneita aineita, kuten kaliumia, fosforia. Pohjavesi, metallit, koru- ja jalokivet, teollisuuskivet ja -mineraalit sekä kiviaines ovat osina geologisia muodostumia. Muovit, polttoaineet, teräs, sementti, betoni, tiili, lasi posliini ja moni muu materiaali valmistetaan geologisista tarveaineista.

Geologia on siis monessa arjen tilanteessa mukana. Kymmenen vuoden kokemukseni kansalaisopistojen opettajana osoittavat, että suomalaiset ovat kiinnostuneita kivistä. Kuinka monella meillä onkaan ulkomailta tai mökkirannalta löytyneitä kiviä kirjahyllyllä, portailla, kaiteilla? Aikuiskoulutus tarjoaa mahdollisuuden kiinnostua kivistä uudelleen omin ehdoin, omien kokemusten ja kivinäytteiden kautta.

\section{KIVI ON KAUNIS}

Kurssini kansalaisopistoissa ovat olleen kivi- ja geologiakursseja, ei siis hiontakursseja. Tämä täytyy tehdä kurssikuvauksissa heti selväksi. Oppilaiden tavoitteena on voinut olla vain oppia, mitä kivinäyte on. Se on jo tärkeä tavoite. Mutta jos näin yksipuolisia ollaan, niin geologia jää jälleen löytymättä. Siksi tunnistamisen tueksi tarvitaan teoriaa siitä, millaisissa oloissa kivet syntyvät.

Geologia voi olla seikkailua mieltä pyörryttävissä ajanjaksoissa ja tapahtumissa. Se avaa monen silmät uudella tavalla. Suomessa on esimerkiksi harmaakivikirkkoja, joiden muurien kivet eivät läheltä katsottuna olekaan harmaita, vaan värikkäitä. Tämän käsityksen oikaiseminen on yksi kivikurssin tärkeistä tehtävistä.

Kivi voi sinänsä olla kaunis, mutta kun tuntee sen historian, se alkaa elää ja kertoilla tarinaansa. Kansalaisopistoissa pitämieni kivikurssien nimenä oli aluksi "Kivilajit kertovat". Geologia onkin parhaimmillaan kiehtova tarina. Silloin ei opettajan tarvitse paljoa vaivautua.

Geologian tutkimuskeskuksen entinen ylijohtaja kirjoitti:

"Me järjestämme kursseja kansakoulunopettajien valmistuslaitoksissa siten, että jokainen vuosikurssi käy noin 20 tunnin kurssin. Näistä on saatu varsin hyviä kokemuksia, sillä on kantautunut yhä enemmän tietoja siitä, että opettajat ovat maantiedontuntien yhteydessä jakaneet ne perustiedot, jotka ovat johtaneet malmikivien löytämiseen".

Noin puolet Suomessa toimineista metallikaivoksista on muuten saanut alkunsa maallikon löytämästä kivestä. Sen kansantaloudellinen merkitys on ollut suuri. Ennen ihmiset asuivat paljolti maalla, nykyään kaupungeissa, joten löytöjä ei enää paljoa tehdä.

\section{TERMIEN KIRJO}

Kuten alussa kävi ilmi, geologia kärsii nimirunsaudesta, vieläpä vieraskielisestä. Tuskin on toista alaa, jolla olisi niin paljon nimiä: kiteet, mineraalit, kivilajit vanhoine ja uusine nimineen sekä synonyymeineen, rakennenimet, maaperän termistö ja fossiilit, joista voi mainita, että yksistään trilobiitteja on 10000 lajia - ja nimeä.

Kerran päätin ryhtyä opettamaan vanhoilla suomalaisilla nimillä, mutta eihän siitä mitään tullut. Sarvivälkekivi tahtoi metamorfoitua amfiboliitiksi, vaalea gneissi (leptiitti) kvartsi- maasälpäliuskeeksi ja vaalea porfyriitti plagioklaasiporfyriitiksi. Nauratin kerran kurssia nimihirviöllä uraliittiplagioklaasi- 
porfyriitti. Entä miltä kuulostaa olivinileukogabronoriitti?

Tiedän suomenkielisten termien vakiinnuttamisen olevan mahdottomuus, enkä enää edes kannata sitä. On parempi käyttää niitä nimiä, jotka geologinen kirjallisuutemme tuntee eli eräänlaisia latinalaisia nimiä. Toki meillä on myös hienoja vakiintuneita suomenkielisiä sanoja, kuten kivikehä (litosfäärilaatta tai epätäsmällisesti mannerlaatta) ja seoskivi (migmatiitti).

Jos kirjoittaa populaaria tekstiä suomeksi, kannattanee käyttää näitä sanoja. Vaikka geologiassa on hybridimagmaa, tekstissä ei tarvitsisi olla hybridikieltä. Kirjoitusta ei tee yhtään oikeammaksi se, että käytetään vierasperäisiä sanoja.

\section{KOKEMUKSIA JA SUOSITUKSIA KIVIKURSSEILLE}

Aikuisten opettamisessa korostetaan nykyään vahvasti opiskelun omaehtoisuutta ja itseohjautuvuutta. Jos oppilaalla ei ole motiivia, ei opettajastakaan ole hyötyä. Opettajaa sanotaan nykyään yhä useammin ohjaajaksi. Ei tulisi kaataa tietoa oppilaiden päähän, vaan ohjata, motivoida, saada kysymään, selittää, neuvoa sekä ennen kaikkea auttaa liittämään uutta tietoa entiseen, auttaa ajattelemaan lyhyesti siis auttaa oppijaa itse rakentamaan tietoa. Tämä konstruktiivinen oppimiskäsitys on opettajille varsin tuttua.

Kivikurssin opettaja voisi myös esitellä kivikirjoja, neuvoa hyvän alkeiskirjan sekä sen, mistä tietoa löytää. On myös hyvä ohjata etsimään kiviä eli sorakuopista, rannoilta, metsäautoteiltä, kallioleikkauksista ja avokallioilta. Lopuksi on hyvä neuvoa, mistä kivimuseoita ja kaivoksia löytää.

Kurssien kokokohtia ovat maastokäynnit. Toinen vetonaula on se, kun kurssilaisia kannustetaan tuomaan omia kivinäytteitään tunnistettaviksi. Oman kiven saama julkinen huomio nostattaa intoa. Kivien tunnistaminen avaa tunneille leppoisan alun. Siitä voi sitten vaivihkaa siirtyä teoriapuolelle. Teoria on tarpeen, mutta sitä ei saa olla liikaa, koska kurssilaiset maksavat pääosin siitä, että oppisivat tuntemaan tavallisia mineraaleja ja kivilajeja. Diaesityksissä, samoin kuin maastokäynneillä voi näyttää kallioperän rakenteita.

Kansalaisopiston kurssi ei kuitenkaan voi olla muuta kuin johdanto aiheeseen ja kiinnostuksen herättäjä. Kiviluonto on niin erilainen kuin elävä luonto, että tavoitteet on pidettävä maltillisina. Alussa on hyvä tehdä selväksi mineraalin ja kivilajin sekä maaperän ja kallioperän ero. Nämä menevät maallikolta helposti sekaisin.

Kertauksen vuoksi: maankuori koostuu periaatteessa vain kahdeksasta alkuaineesta. Vaikka mineraaleja on kaikkiaan noin 4 000, kivilajeja muodostavia mineraaleja on vain 20-40. Kaikki kivilajit voidaan jakaa kolmeen ryhmään: magma-, sedimentti- ja metamorfiset kivet. Käytännöllisesti ajateltuna koko maapallo on vain yhtä ainutta kivityyppiä, magmakiveä. Maan pintakuoren kivilajeista melkein kaikki on basalttia, graniitin sukuisia kiviä, hiekkakiveä, savikiveä tai kalkkikiveä. Esimerkiksi Keravan kallioperäkarttalehden (1: 100 000) kivilajeista arviolta 90 prosenttia on sellaisia, joiden päämineraalit ovat kvartsi, maasälvät ja kiille. Pääkaupunkiseudun kivilajit voi luokitella 10-15 nimikkeen alle.

Se, kuinka hyvin oppijat oppivat sitten tunnistamaan graniitin ja gneissin, riippuu pitkälti siitä, kuinka motivoituneita he ovat ja kuinka paljon opettaja "tuhlaa" aikaa teoriaan. Tasapaino teorian ja käytännön välillä on tavoiteltavaa. Kansalaisopistojen luonne on harrastepohjainen opetus. Kivikunnan opiskelussa korostuu kertauksen merkitys ehkä enemmän kuin muissa kouluaineissa. Pitäisi oppia yhdistämään nimi kiveen ja kivi nimeen yhä uudelleen ja uudelleen.

\section{OPPIMISSYKLI TYÖMUOTONA}

Kasvatustieteissä on kehitetty erilaisia opiskelemiseen ja opettamiseen liittyneitä työmuotoja. Yksi geologiaan soveltuva muoto on oppimissykli. Tässä oppilaat saavat vapaasti yrittää, erehtyä ja keskustella; tehdä havaintoja, kysymyksiä ja kokeilla sekä 
oppia soveltamaan opittua käytäntöön. Se muistuttaa tavanomaista luonnontieteellistä työskentelyä. Tämän pitäisi kehittää ajattelutaitoja ja soveltua kaikille opiskeluasteille. Lähteinä olen käyttänyt Sahlbergin (1990), Ahteen (1994) ja Hildénin (1997) töitä.

Syklin ensimmäinen vaihe on tutkimus. Oppilaalle annetaan jokin tutkimisohjelma. Erilaisia tutkimuskohteita ja -välineitä annetaan runsaasti. Alkajaisiksi oppijoille voi antaa esimerkiksi lasiset purkit, joissa on mineraalinäytteitä, sulakkeen, rautanaulan, magneetin, suurennuslasin ja purkin apteekista saatavaa kymmenprosenttista suolahappoa. Sitten voi sanoa: havainnoikaa, hapuilkaa, tehkää kokeita, tutkikaa ja katsokaa, mitä tapahtuu. Keskustelkaa, kysykää, tehkää muistiinpanoja. Yksityiskohtaisia ohjeita ei heti anneta.

Eihän kuuluisa suomalainen geologi Sederholmkaan saariston kalliorakenteisiin tutustuessaan ensin ymmärtänyt paljoa näkemästään. Hän toki tunnisti mineraalit ja kivilajit, muttei sitä, mitä muinaisuudessa oikein oli tapahtunut. Hän sanoi, että ei edes yksi ihmisikä riittäisi selvittämään kaikkea. Alussa vallitsi kaaos, ja asioita täytyi laittaa jonkinlaiseen järjestykseen.

Kivikunnan perusasioiden oppimisessa yritetään siis jäljitellä tätä; ei anneta mitään valmiina. Oppijat ovat kuin ensimmäisiä luonnontutkijoita uuden ajan alussa. Saamme ehkä kuulla omituisia hypoteeseja. On huomattava, että ne ovat omituisia vain opettajan, ei opiskelijoiden mielestä. Opettaja voi tarvittaessa ohjata tutkimusta mielekkääseen suuntaan. Jos opettaja siten sanoo, että "naarmuttakaa", joku alkaa ehkä naarmuttaa magneetilla mineraalia, kunnes sattumalta huomaa, että näyte tarttuikin siihen. Tämänkin havainto kirjataan ylös.

Jotain paria tai ryhmää voi kehottaa laittamaan esineet naarmutuskokeen perusteella kovuusjärjestykseen, toisia luokittelemaan pyöristyneet ja kulmikkaat, vaaleat ja tummat tai metallihohtoiset ja ei-metallihohtoiset kappaleet erilleen. Tämä ei ole kaukana entisaikojen luonnontutkijoiden käy- tännöstä, jolloin mineraalit, kivilajit, fossiilit ja kivikirveetkin luokiteltiin kaikki yhteen ja samaan ryhmään. Näin niille annettiin yhteisnimi fossiili, mikä tarkoittaa maasta kaivettua.

Oppilaat saavat keskustella vapaasti ja saavat myös itse päättää, mitä seikkoja haluavat tutkia. Kukin pari tai ryhmä voi edetä omaan suuntaansa. Tärkeintä on, että tässä tutustutaan erilaisiin mineraalikunnan ilmiöihin, niiden yksinkertaisiin tutkimusvälineisiin, tehdään kokeita, keskustellaan ja kirjataan tulokset ja olettamukset ylös.

\section{KÄSITTEIDEN MUODOSTAMINEN JA SOVELTAMINEN}

Pienen tutkimisen jälkeen siirrytään oppimissyklin toiseen vaiheeseen, käsitteiden muodostamiseen. Oppilaille selitetään, että heidän tekemänsä kokeet ovat olleet keinoja tunnistaa mineraaleja. Selitetään, mitä mineraali on, mistä alkuaineista tai ioneista se koostuu. Sitten selitetään käsitteet viiru eli mineraalijauheen väri, kovuus, lohkeavuus, kiilto ja muut mineraalien tuntomerkit, jotka siis poikkeavat oleellisesti eliökunnan tuntomerkeistä.

Kivi on oma maailmansa, kiteinen, kiteiden maailma. Sen kidemuodot ja lohkopinnat heijastavat kiven sisäistä järjestystä. Eri mineraaleilla on erilaiset ominaisuusyhdistelmät. Mitä useamman ominaisuuden määrittää, sitä todennäköisemmin pystyy tunnistamaan mineraalin.

Erityisesti kurssilaisia rohkaistaan selittämään tarkasteltavia käsitteitä omien kokeilujensa pohjalta: miksi tapahtui niin ja niin, kun tehtiin näin ja näin. Heidän selityksensä saattavat olla joskus alkemistisia. Opettajan tehtävä on tulkita tulokset nykytiedon mukaisiksi. Monien nykykäsitysten syntyminenhän on kestänyt vuosikymmeniä tai -satoja. Oppilailla ei ole yhtä paljon aikaa. Opettaja jouduttaa nykyaikaan pääsemistä. Tuntien alussa oppijat ovat alkemisteja, opussa ihannetapauksessa melkein mineraalikemistejä. Oppilaille voi näyttää myös mineraalinmäärityskaaviota tai opetusvideon, jos sellainen on. 
Kolmas työvaihe on käsitteiden soveltaminen. Nyt oppijoille annetaan samoja mineraaleja kuin alussa, mutta erivärisinä ja kokoisina rakeina samoin kuin aivan uusia mineraalejakin, ja tehtävänä on määrittää ne. Vasta tässä vaiheessa heille annetaan selkeästi määriteltyjä tehtäviä.

Samaa työmuotoa voi käyttää myös kivilajien opiskelussa. Nyt ensivaiheessa mineraalien sijaan annetaan karkearakeisia kivilajeja, joiden mineraalit oppilaat (ideaalitapauksessa) jo tuntevat. Toisessa vaiheessa selitetään muun muassa kivilajin käsite, niiden kolmijako, rakenne ja syntytavat. Kolmannessa, soveltavassa vaiheessa voi antaa määritettäväksi keskirakeisia kivilajeja, joissa mineraalit voivat olla vierasmuotoisiakin, saman kivilajin eri rakenneja värimuunnoksia.

\section{LOPUKSI}

Oppimissykli kehittää ajattelutaitoja konkreettiselta tasolta käsitetasolle sekä kannustaa oppilaita soveltamaan käytäntöön jo oppimiaan asioita. Lisäksi se kehittää vuorovaikutusta luonnon, toistensa ja opettajan kanssa sekä tutustuttaa oppilaat luonnontieteelliseen menetelmään ja lyhyesti jopa luonnontieteiden historiaan.

Sahlbergin (1990) mukaan "useissa tutkimuksissa on havaittu työtavan tuottavan parhaita oppimistuloksia myös tiedollisella alueella”. Tekemällä käytännössä oppii usein paremmin kuin kuuntelemalla luentoa. Tekemällä oppiminen onkin kansalaisopistojen peruskauraa. Teoriaa ja luentojakin toki tarvitaan.

Mineraalien ja kivilajien oppiminen ei siis ehkä ole kovin helppoa. Ihmelääke siihen on motivaatio ja kertaus.

Jukka Hildén

FM, geologi

\section{KIRJALLISUUS}

Ahtee, M., Kankaanrinta, I.-K. \& Virtanen, L. (1994). Luonnontieto koulussa. Otava: Keuruu.

Hildén, J. (1994). Lohkaretutkimuksen suuntaviivoja. Pro Gradu -tutkielma. Helsingin yliopisto, geologian laitos, geologian ja paleontologian osasto.

Hildén, J. (1997). Luonnonmaantiede, geologia ja opetustyö. Seminaariesitys. Helsingin yliopiston opettajankoulutuslaitos, monimuotoyksikkö.

Marmo, V. (1968). Maantieteen opetus ja geologia. Terra $80: 2$

Sahlberg, P. (1990). Luonnontieteiden opetuksen työtapoja. Valtion painatuskeskus. Kouluhallitus. Finiste. 